\title{
Reseña de Se levanta el clamor popular. Experiencias del pueblo organizado durante el gobierno de los mil días 1970-1973 de Enrique Gatica (Eds).
}

Review of Se levanta el clamor popular. Experiencias del pueblo organizado durante el gobierno de los mil días 1970-1973 by Enrique Gatica (Ed).

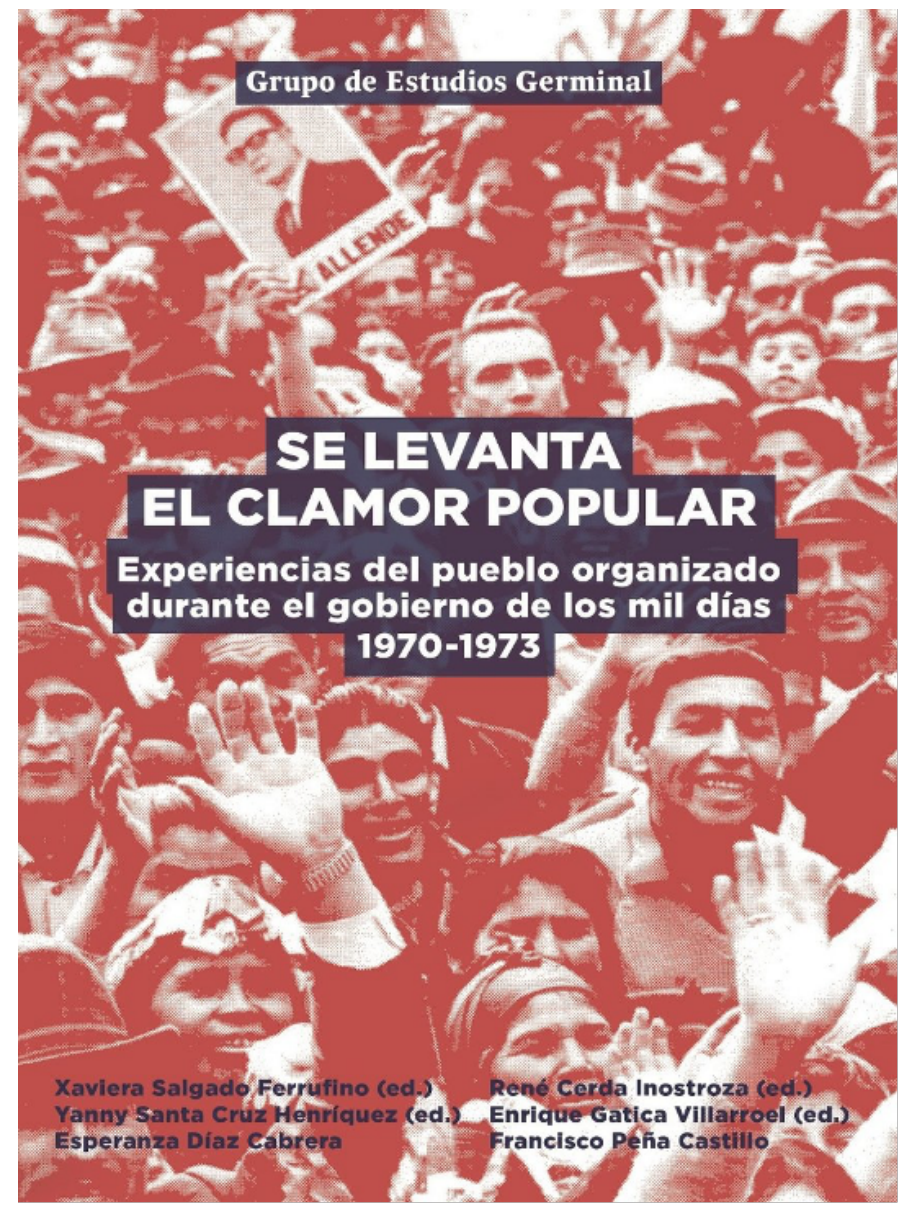

Gatica, E., Cerda, R., Salgado, X., Santa Cruz, Y., Peña, F., \& Díaz, E.

Se levanta el clamor popular: Experiencias del pueblo organizado durante el gobierno de los mil días 1970-1973.

Talleres Sartaña, 2019, 238 págs.
Este libro que se expondrá a continuación fue escrito de forma grupal por jóvenes historiadores titulados del programa de Magister de Historia de la Universidad de Santiago de Chile (USACH) conformados en el Grupo de Estudios Germinal. Su propuesta es clara como significativa para la historiografía social chilena, contribuyendo a (re) pensar los tiempos de la Unidad Popular (UP) más allá de la conocida "historia desde arriba", la cual supone que las grandes transformaciones ejercidas por este gobierno devienen exclusivamente por sus personalidades políticas estatales, encarnadas en el presidente Salvador Allende.

En la composición de seis ensayos, este libro muestra una variedad de sujetos sociales que pulularon y construyeron una experiencia de organización popular durante el proceso histórico de la UP. Este escrito inicia con el estudio de Esperanza Díaz, quien analiza cómo las Juntas de Abastecimiento y Precios fueron una institución que promovió desde las bases populares una mayor organización y politización femenina, tensionando los discursos tradicionales de género, aunque no garantizando una liberación feminista del patriarcado, más bien ajustando sus acciones dentro de estos roles de maternidad impuesto a las mujeres. En un segundo capítulo, Enrique Gatica expone cómo se desarrolló la Toma de la Población Nueve de Mayo, ubicada en la actual comuna de Colina, a través de ello, aborda como los pobladores aprovecharon los tiempos de la Unidad Popular para finalmente ser visibilizados por el Estado, 
desde una organización completamente "desde abajo", y con algunos apoyos de alcaldes y diputados de la UP, se muestra una historia que enfatiza en el empoderamiento de estos sujetos sociales invisibilizados hasta ese momento. Desde una problematización teórica sobre el concepto del "paternalismo industrial”, René Cerda analiza la politización y organización obrera-minera, anterior y durante el triunfo electoral de la Unidad Popular, desde esta perspectiva este historiador sostiene que desde los mineros se desarrollaron previamente algunos lineamientos postulados en la agenda política de Salvador Allende, como lo fue la nacionalización del cobre. En el capítulo siguiente, Xaviera Salgado explora la experiencia popular y obrera en la conformación de los Cordones Industriales de Cerrillo-Maipú (CCM), develando una transformación de estos sujetos entre un respaldo al mandato del presidente de la UP, hacía una crítica radical por su negociación política con los grupos empresariales que causó un retroceso del proyecto de estatización industrial, ante ello se logra ver cómo estos obreros armaron un concepto de revolución alternativo al desarrollado por el programa político de Allende. Proponiendo un cuestionamiento a la generalización de la categoría etaria juvenil, Yanny Santa Cruz señala cómo la politización y radicalización estudiantil no debe leerse como la consecuencia de un evento histórico nacional como lo fue el ascenso del socialismo en Chile, sino que para comprender la militancia de los estudiantes secundarios es preciso analizar los repertorios políticos introducidos desde sus experiencias personales: lazos familiares, nexo político-institucional escolar y su vinculación con la cotidianidad de la sociedad. Finalmente, Francisco Peña analiza comparativamente la experiencia de tres grupos de izquierda armada latinoamericana (MIR, ELN y la VOP) con respecto a la vía chilena al socialismo, tomando en cuenta que esta coyuntura histórica supuso una completa reorientación respecto al discurso de violencia armada al interior de estos grupos, logrando explicar los factores que permitieron estas transformaciones o persistencia de estas prácticas.
Un factor que une a todos estos investigadores es su enfoque historiográfico que, exhibe la historicidad de estos sujetos populares, y sus conexiones con las transformaciones sociales del gobierno de Salvador Allende durante el 1970-1973. Como afirma su grupo editorial en las primeras páginas de este escrito:

Comenzamos a mirar a la Unidad Popular,
pero ansiando quitar el peso de la derrota.
Intentamos imaginarnos en esa coyuntura,
construyendo una sociedad nueva. Y nos
dimos cuenta que había mucho más que
Allende: que el compañero presidente era
el rostro de un periodo, pero que éste había
sido construido por miles y miles, cuyas
historias - en la mayoría de los casos- no
habían sido recuperadas ( $\mathrm{p}$. 16).

Se trata no solo de un ejercicio historiográfico, sino que también antropológico por parte de los mismos historiadores, quienes comienzan a generar preguntas referidas a su presente y a cómo se entiende la historia de la Unidad Popular en la academia. Para los investigadores más jóvenes que, no fueron testigos experimentales de esos tiempos, se les hace más complejo estudiar esta coyuntura histórica, dado que solamente nos enfrentamos a un relato visto "desde arriba", o a una memoria conservadora que afirma que el plan de Salvador Allende y su gobierno era desatar el caos en el país para convertirlo en otro satélite latinoamericano del comunismo internacional. Existen muchos estigmas sobre la historia de este proceso histórico que terminan por subordinar la experiencia y agencia del pueblo durante estos episodios.

Para enfrentar este desafío, estos investigadores privilegiaron una conexión con sus sujetos de estudios, entrevistando a testigos y participantes de tomas de terrenos, obreros de la minería, militantes de partidos políticos y grupos no institucionales, entre otros. De esta manera, se rescatan estas voces que no han sido del todo recuperadas por la historiografía referida a este contexto, la memoria de los sectores populares, y cómo su agencia fue elemental para explicar el desarrollo y debacle de la Unidad Popular. En su mayoría 
se pueden visualizar, como argumenta Steve Stern, memorias emblemáticas (Stern, 2009, p. 147) que refieren al pasado socialista como una experiencia abiertamente popular, que dotan de mayor agencia histórica al pueblo que a las autoridades de la Unidad Popular.

Desde mujeres organizadas para evitar la escasez de alimentos y el mercado negro en estos productos indispensables para vivir, hasta la trascendencia de la organización y politización minera para el proyecto de nacionalización del cobre, este escrito traza un relato que conecta a estos sujetos populares en lazos que van más allá de lo dictaminado por el aparato estatal. Aunque el libro en cuestión se divide en capítulos separados, se pueden observar la aparición de instituciones y personas que traspasan zonas especificas de acción, y se instalan en las memorias de diversos sujetos populares en distintos lugares del país. La Junta de Abastecimiento y Precios (JAP) aparece reiterativamente como soporte en las luchas de los mineros en el norte del país y en los Cordones Industriales en el sector poniente de la capital chilena. Los estudiantes secundarios relatan como en sus Trabajos Voluntarios se nutrieron de las experiencias de otros sujetos populares, y comprendieron que mediante esta práctica se estaba aportando a la trascendencia histórica que podría alcanzar su acción para el gobierno y el buen vivir de estos sectores.

Con estos lazos se puede leer una experiencia y organización popular muy fuerte, que como se apreció anteriormente, se conformó alternativamente a las directrices del Estado de la UP. De hecho, en muchas ocasiones los sectores populares fueron críticos con este último, mostrando cómo el concepto revolucionario promulgado por el propio Allende contenía factores de conservadurismo, en contraste a un radicalismo de estos sujetos. Una parte de los pobladores de la toma Nueve de Mayo no reconoció la función del presidente en las actividades de la toma, cuestionando el nombre que se le puso a esta en sus inicios - "Población Gladys Marin", una reconocida diputada del Partido Comunista durante esa época (p. 73). Asimismo, la resistencia del Cordón Cerrillos-Maipú ante el retroceso del gobierno en materias de estatización de industrias, levantaron una paralización indefinida, sosteniendo que no reconocerían la decisión de Allende en retomar las actividades laborales (p. 147). Por tanto, mediante este libro se puede tensionar la unidad del proyecto de la UP, aunque dicha diversidad nunca atentó con una base social de fondo. Efectivamente, así como existieron cuestionamientos a la arquitectura política de la Unidad Popular, también fue mayor el entusiasmo y compañerismo que despertó este proceso de socialismo democrático, develando una reducción en la distancia entre la denominada clase política con el pueblo.

De esta forma, el pueblo forma parte fundamental de este libro, logrando rescatar voces sepultadas por la historiografía. Anteriormente, se afirmaba que este era un desafío antropológico en todas sus letras, en tanto incluía a los investigadores y a los testigos en la construcción de este relato bien pulido por este escrito. Por medio de este libro se confirma el carácter colectivo de la memoria, posibilitando un cauce enriquecedor sobre los acontecimientos que se desarrollaron en este tiempo histórico. Sin embargo, los estudios de memoria envuelven más complejidades que problematiza la metodología que siguieron estas investigaciones. Como demuestra el ensayo sobre la Toma de Nueve de Mayo de Enrique Gatica, efectivamente hay una permeación de los relatos y comportamientos en el presente por los hechos traumáticos de la dictadura cívico-militar.

En un esfuerzo que desarrollan una parte de estos investigadores con sus sujetos de estudio, se coloca atención a cómo se desarrolló esta experiencia popular en dictadura, y todas las restricciones y violencias que este periodo supuso. Para la historiografía actual es indispensable pensar el periodo de la Unidad Popular sin concebir las dramáticas consecuencias con el Golpe de Estado y la dictadura cívico-militar. De esta forma, se logra ver en los entrevistados una suerte 
de trauma que imposibilita analizar cómo fue la prístina experiencia popular durante esos tiempos, puesto que en su mayoría estos relatos están inundados de una derrota anunciada por la violencia dictatorial. Aunque en algunos casos esta sociabilidad popular pervive durante el régimen, gran parte de estas energías revolucionarias y la historicidad de la agencia popular terminan siendo mermadas en contraste con los tiempos de la Unidad Popular. Pese a ello, este libro logra sortear estas dificultades que señalan los estudios de memoria, y propone una mirada que no ha sido del todo reconocida por la academia historiográfica chilena, ni latinoamericana.

\section{Referencias}

Gatica, E., Cerda, R., Salgado, X., Santa Cruz, Y., Peña, F., \& Díaz, E. (2019). Se levanta el clamor popular: Experiencias del pueblo organizado durante el gobierno de los mil días 1970-1973. Talleres Sartaña.

Stern, S. (1998). De la memoria suelta a la memoria emblemática: hacia el recordar y el olvidar como proceso histórico (Chile, 1973-1998). En E. Jelin (Comp.) Las conmemoraciones: las disputas en las fechas 'infelices', (pp.11-33) Siglo XXI.

\section{Conflicto de intereses}

El autor declara que no existe conflicto de interés posible.

\section{Financiamiento}

No existió asistencia financiera de partes externas al presente artículo

\section{Agradecimientos}

El autor agradece a familiares y amigos. Particularmente a Carlos y Javier por la información del libro cuando éste se publicó, y la motivación a leerlo crítica y detenidamente. 